\title{
Flexibility in Faculty Work-Life Policies at Medical Schools in the Big Ten Conference
}

\author{
Julie L. Welch, M.D., Sarah E. Wiehe, M.D., M.P.H., ${ }^{2}$ \\ Victoria Palmer-Smith, M.D., and Mary E. Dankoski, Ph.D. ${ }^{3}$
}

\begin{abstract}
Purpose: Women lag behind men in several key academic indicators, such as advancement, retention, and securing leadership positions. Although reasons for these disparities are multifactorial, policies that do not support work-life integration contribute to the problem. The objective of this descriptive study was to compare the faculty work-life policies among medical schools in the Big Ten conference.

Methods: Each institution's website was accessed in order to assess its work-life policies in the following areas: maternity leave, paternity leave, adoption leave, extension of probationary period, part-time appointments, parttime benefits (specifically health insurance), child care options, and lactation policy. Institutions were sent requests to validate the online data and supply additional information if needed.

Results: Each institution received an overall score and subscale scores for family leave policies and part-time issues. Data were verified by the human resources office at 8 of the 10 schools. Work-life policies varied among Big Ten schools, with total scores between 9.25 and 13.5 (possible score: 0-21; higher scores indicate greater flexibility). Subscores were not consistently high or low within schools.

Conclusions: Comparing the flexibility of faculty work-life policies in relation to other schools will help raise awareness of these issues and promote more progressive policies among less progressive schools. Ultimately, flexible policies will lead to greater equity and institutional cultures that are conducive to recruiting, retaining, and advancing diverse faculty.
\end{abstract}

\section{Introduction}

A MONG FACULTY IN ACADEMIC MEDICINE, women lag behind men in several indicators, such as advancement, retention, and leadership positions. The Women in U.S. Academic Medicine Statistics and Benchmarking Report 2008-2009 from the Association of American Medical Colleges (AAMC) indicates that although the absolute number of women faculty has never been higher, the ratio of women to men does not reflect the general population. ${ }^{1}$ For example, comparing 1998-1999 with 2008-2009, there was a 64\% increase in women full professors, a $63 \%$ increase in women department chairs, and a remarkable $140 \%$ increase in women medical school deans. Without reading further, we might conclude that there is no longer a problem. Despite these gains, the actual percentage of women in each category remains low. In 2008-2009, women comprised $18 \%$ of full professors $(5,361$ of 29,839$), 13 \%$ of department chairs (372 of $2,952)$, and $12 \%$ of medical school deans (16 of 131). It is only because women lagged so far behind men a decade ago that the 10-year gains appear so impressive.

Explanations for such gender differences are multifactorial, and women faculty face cumulative career disadvantages over time. Many disadvantages stem from unconscious biases that cause both men and women to underestimate the competence of women and overestimate that of men. ${ }^{2}$ In a study comparing applicants to a postdoctoral fellowship program, women needed to be 2.5 times more productive to receive the same competence score as men. ${ }^{3}$ Similarly, a study of recommendation letters for faculty hired at a U.S. medical school revealed that letters for women were shorter, contained more "minimal assurance language," gendered terms, and "doubtraisers" than letters for men. ${ }^{4}$ The implications of bias in evaluations are profound in terms of promotion and tenure, and studies have documented that despite similar achievements, women are less likely than men to be advanced in academic rank. ${ }^{5}$ Such differences are influenced by the lack of or ineffectiveness of mentoring available to women faculty, ${ }^{6}$

${ }^{1}$ Department of Emergency Medicine, ${ }^{2}$ Children's Health Services Research, Department of Pediatrics, and ${ }^{3}$ Office of Faculty Affairs and Professional Development and Department of Family Medicine, Indiana University School of Medicine, Indianapolis, Indiana. 
which may also help explain gender differences in such issues as first and senior authorship in journal articles ${ }^{7}$ and progression from career development awards to National Institutes of Health (NIH) R01 funding. ${ }^{8}$

Another contributor to gender gaps is that policies to support work-life integration differentially impact women and men. Across most households, women tend to disproportionately carry the duties of caring for the home and family; this trend holds even when dual career partners work similar hours. ${ }^{9}$ Raising young children often competes with the tenure clock, and faculty who are mothers face more barriers to advancement compared to faculty who are fathers. ${ }^{10}$ Across higher education, attrition of women faculty with children is higher than that for men. ${ }^{11}$ Previous generations of faculty were often assumed to have almost unlimited time to devote to professional life because of having a spouse at home to manage the family. This is no longer reality for the younger generation of professionals, who often have employed spouses and together desire to work as a team to integrate career and home life. This is especially true for professional women: in science and engineering fields today, about half the spouses of men faculty work full-time, whereas about $90 \%$ of the spouses of women faculty are employed full-time. ${ }^{12}$

For reasons such as these, flexible policies are being called for increasingly in both the corporate world and higher education by women and men in various career stages: junior faculty with young children, faculty in midcareer caring for aging parents, and faculty seeking phased retirement. ${ }^{13}$ Thus, although work-family issues differentially impact women they are not women's issues. Many corporations assert they have a competitive edge by using flexible policies to recruit top talent and reduce turnover. ${ }^{14}$ In higher education, the push for greater flexibility coincides with increasing faculty diversity. A report from the American Council on Education (ACE) in collaboration with the Alfred P. Sloan Foundation entitled, "An Agenda for Excellence: Creating Flexibility in Tenure Track Faculty Careers," was endorsed by a panel of chancellors and presidents of major universities across the country and led to the development of many new policies at several institutions. ${ }^{15,16}$ It will be interesting to note whether the institutions funded under this initiative will realize an increase in the recruitment, retention, and advancement of women faculty.

Despite these calls for increasing flexibility, few investigators have systematically compared policies among institutions. One notable exception is the study conducted by Bristol et al. ${ }^{17}$ that examined work-life policies at the top 10 medical schools. Using a modified rubric from their article, the objective of the current study was to compare work-life policies among medical schools in the Big Ten Conference.

\section{Materials and Methods}

\section{Study design and population}

We performed a descriptive study of university work-life policies for medical schools in the Big Ten Conference. The Big Ten Conference comprises 11 institutions primarily located in the Midwest that compete in National Collegiate Athletic Association (NCAA) Division I athletic programs. All but 1 are public, with undergraduate enrollments between approximately 20,000 and 40,000 students; Northwestern University is a private/nonsectarian university with an undergraduate enrollment of approximately $8000 .{ }^{18}$ The endowments of these universities range between $\$ 935$ million and $\$ 7.6$ billion. ${ }^{19}$ Ten of the 11 universities have medical schools and were included in this study: Indiana University, Michigan State University, Northwestern University, Ohio State University, Penn State University, University of Illinois, University of Iowa, University of Michigan, University of Minnesota, University of Wisconsin. Purdue University is in the Conference but does not have a medical school and thus was omitted.

\section{Procedure}

We accessed each institution's website (February 2009June 2009) and searched for information on policies in the following areas: maternity/paternity/adoption leave, extension of probationary period, part-time appointments, parttime health benefits, child care options, and lactation policy. These policy categories were adapted from the study by Bristol et al. ${ }^{17}$ assessing work-life policies of the "Top Ten" medical schools. Specifically, we modified categories for parttime appointments, part-time tenure track, and part-time health benefits and added a category for lactation policy (Table 1). Because there were wide variations among institutions in the definition of part-time, we used each institution's own definition when relevant; when a specific percent of fulltime employment (FTE) was required for determination of a particular benefit, this was recorded in the data.

We mailed a summary of each institution's online data to a faculty affairs representative for verification and additional information. In the letter, we described the purpose and policies of interest and summarized the information gathered online. Adjacent to each policy was a yes/no question to indicate whether the information was correct. We encouraged adding or changing incorrect information and followed up with phone calls and emails if a response was not received.

Each policy for each institution was scored on a scale as described in the Policy Scoring Key (Table 1), with higher scores indicating greater flexibility. Three independent observers applied the scoring key to the policies, and discrepancies were resolved by consensus. This scoring system was modified from Bristol et al. ${ }^{17}$ to include additional policies. Subtotals were tallied for family leave policies and policies specific to part-time faculty. Category scores ranged from a minimum of 0 to maximum of 1,2 , or 3 . For example, family leave policies limited to coverage provided by the Family Medical Leave Act (FMLA) were rated as 0 to reflect this as baseline, with more flexible policies rated as 1,2, and 3. A total possible score ranging from 0 to 21 was calculated for each institution based on the addition of average leave policies, extension of probationary period, part-time appointment, part-time tenure track, part-time health benefits, child care options, and lactation policies.

Family leave (maternity, paternity, and adoption) policies were quite variable depending on full-time or part-time status and the length of time since date of hire. In order to fully evaluate these policies over the span of a faculty career, we determined an average score for each policy based on four variables: part-time faculty, full-time faculty at day 1 , after 1 year, and after 2 years of hire. An average score was calculated for maternity, paternity, and adoption leave ranging from 0 to 3 , then totaled for all leave policies for a possible score of 9 . 
Table 1. Work-Life Policy Scoring Key

\begin{tabular}{|c|c|}
\hline Policy & Scoring definition \\
\hline \multirow[t]{4}{*}{ Maternity leave } & 0 FMLA \\
\hline & 1 FMLA and accrued sick/disability payment \\
\hline & $26-8$ weeks paid leave \\
\hline & $3>8$ weeks paid leave \\
\hline \multirow[t]{4}{*}{ Paternity leave } & 0 FMLA \\
\hline & 1 FMLA and accrued sick/vacation payment \\
\hline & $2<4$ weeks paid leave \\
\hline & $3>4$ week paid leave \\
\hline \multirow[t]{4}{*}{ Adoption leave } & 0 FMLA \\
\hline & 1 FMLA and accrued sick/vacation payment \\
\hline & $23-8$ weeks paid leave \\
\hline & $3>8$ weeks paid leave \\
\hline \multirow[t]{4}{*}{ Extension of probationary period } & $0<1$ year \\
\hline & 11 year extension on request \\
\hline & 21 year automatic extension \\
\hline & 3 No probationary period \\
\hline \multirow[t]{3}{*}{ Part-time appointments } & 0 No part-time appointments available \\
\hline & 1 Part-time appointments for special circumstances $O R$ with time limit \\
\hline & 2 Part-time appointments with no time limit \\
\hline \multirow[t]{2}{*}{ Part-time tenure track } & 0 No part-time tenure track \\
\hline & 1 Offer part-time tenure track \\
\hline \multirow[t]{4}{*}{ Part-time health benefits } & 0 No part-time benefits offered \\
\hline & 1 Benefits offered proportional to FTE $\geq 75 \%$ \\
\hline & 2 Benefits offered proportional to FTE $\geq 50 \%$ \\
\hline & 3 Benefits offered proportional to FTE $<50 \%$ \\
\hline \multirow[t]{3}{*}{ Child care options } & 0 No direct affiliation with child care centers \\
\hline & 1 Affiliated child care centers available with no financial aid or discounts \\
\hline & 2 Affiliated child care centers available with financial aid or discounts or both \\
\hline \multirow[t]{2}{*}{ Lactation policy } & 0 General policy with no online listing of dedicated space for breast pumping \\
\hline & 1 Listing of dedicated spaces available for breast pumping \\
\hline
\end{tabular}

Adapted and modified from Bristol et al. ${ }^{17}$

FMLA, Family Medical Leave Act; FTE, full-time employment.

We calculated an additional score (range 0-15) for policies specific to part-time faculty, including maternity leave, paternity leave, adoption leave, part-time appointments, parttime tenure track, and part-time health benefits.

\section{Results}

Data were verified at 8 of 10 schools (Table 2). A description of each policy and its score can be found in the Appendix (supplemental material available online at www .liebertonline.com), along with the source. If policy data were unavailable, the entry was left blank or marked as not applicable. In general, the online accessibility of policy data was time consuming and required searching multiple different web pages for each institution. Additionally, finding the correct contact person to verify the policies posed a challenge at a few institutions. Several institutions had a work-life website, but Michigan State proved to be the most progressive in compiling a well-designed, comprehensive, easily accessible Work/Life Guide for Faculty \& Staff on their Family Resource Center website.

The scores are presented in descending order of total score, with Ohio State receiving the highest overall score of 13.5, followed by Michigan State at 13.25 and University of Wisconsin at 12.25 (Table 2). Indiana University had the lowest total score of 9.25 .

\section{Family leave policies}

Penn State University had the highest average score of 6 for family leave policies and is the only institution to offer paid leave to both full-time and part-time faculty without requiring a length of service to qualify (Table 3). Three additional institutions recognize part-time faculty but fail to offer paid leave from day 1 of hire (Michigan State: 5.25, Ohio State: 4.5, University of Minnesota: 3.75). The difference in scores results from Michigan State offering longer paid maternity leave and Minnesota offering less paid adoption leave. In addition to Penn State, University of Wisconsin is the only institution offering paid family leave to full-time faculty from day 1 of hire. Indiana University received the highest individual category score for family leave policies, offering 12 weeks of paid leave to full-time academic faculty after 2 years of full-time service; part-time faculty must take unpaid family leave through FMLA. The remaining institutions do not offer paid family leave to part-time faculty.

\section{Part-time appointments}

Part-time appointments are offered at all 10 universities, but tenure track appointments are available to part-time faculty by 6 of the universities. No tenure track appointments are available for part-time faculty at Indiana University or Northwestern. The University of Minnesota indicates a 

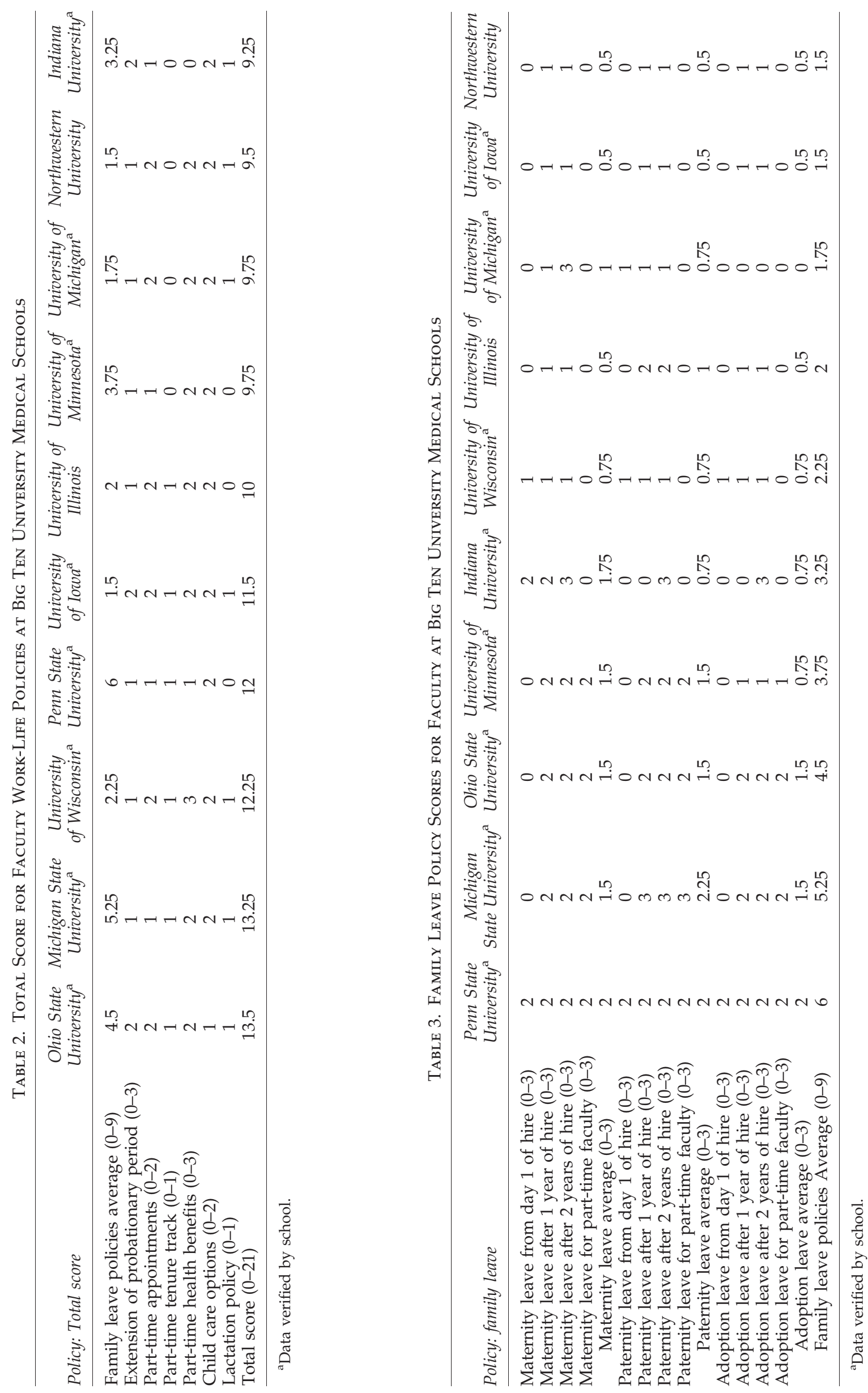
faculty member "must be $50 \%$ to be tenure eligible" and University of Michigan indicates "tenure-track appointments of at least $80 \%$ effort accumulate time on the tenure clock."

\section{Part-time health benefits}

Only 1 of the 10 schools, Indiana University, does not offer health benefits for faculty with $<1.0$ FTE appointments. University of Wisconsin offers health benefits to faculty at $\geq 21 \%$ FTE, which is the most inclusive policy. Penn State offers health benefits to part-time faculty at $\geq 75 \%$ FTE, and the rest offer health benefits to faculty at $\geq 50 \%$ FTE.

\section{Policies for part-time faculty}

The two institutions receiving the highest score for these categories are Michigan State and Ohio State (score of 11) (Table 4). Penn State (score of 9) and University of Minnesota (score of 8) also had relatively more supportive policies for part-time faculty. The lowest score of 1 was Indiana University, which offers part-time appointments at the discretion of the chair. Of note, the definition of "part-time" varied not only between institutions but often within an individual institution depending on the policy. The definition of "parttime" ranged from $21 \%, 50 \%, 75 \%$, to $89.9 \%$ FTE for various policies.

\section{Extension of probationary period}

University of Iowa and Ohio State offer automatic extension of the probationary period for up to 1 year for events such as the birth of a child. Additionally, Ohio State allows for 1 year per child, up to 3 years total. All other schools require a petition or request to grant an extension.

\section{Child care options}

Child care options are consistently offered at all 10 universities. The majority of websites provided valuable resources for on campus and off-campus affiliated child care centers, with most offering discounts or financial aid to faculty.

\section{Lactation policy}

Seven schools supplied information on designated lactation rooms on campus.

\section{Discussion}

Work-life policies varied among Big Ten universities, with total scores between 9.25 and 13.25 (possible range 0-21). Subscores were not consistently high or low within institutions. For example, those with progressive family leave policies often had less progressive policies relating to part-time faculty and other work-life policies, and vice versa. There was no institution that was an outlier in either direction.

Compared with the study by Bristol et al. ${ }^{17}$ on top 10 medical schools' work-life policies, the Big Ten universities had policies with slightly higher scores and demonstrated less variability (after rescoring to meet the initial Bristol et al. scoring system). The scoring system we used contained additional metrics, including the time from hire in which family leave policies were available and whether leave policies were available to part-time faculty. We also incorporated addi-

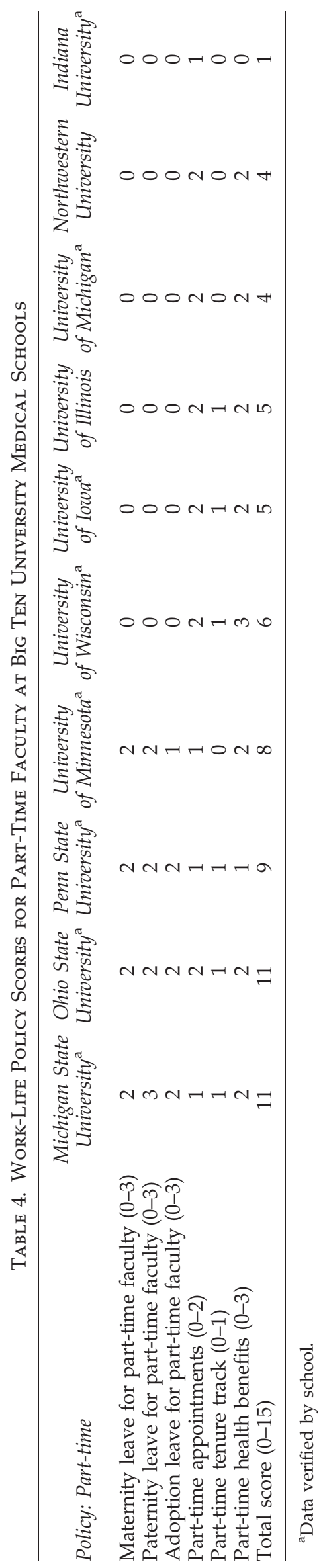


tional part-time policies relating to tenure track appointments and health benefits.

Ultimately, these policies are important because of the flexibility they offer, which has become highly important to many faculty members. Such policies are evolving as the demographics of the faculty shift toward greater diversity by gender, race/ethnicity, and generation. Institutional leaders, such as senior faculty and department chairs, are generally male members of the Boomer generation, whereas junior faculty are generally members of Generation X. These generations tend to have different expectations about authority, self-sacrifice, mentoring, and work-life balance. ${ }^{20}$ This can create significantly different expectations about the "the ideal worker," with many junior faculty demanding greater flexibility and integration of personal and professional roles. ${ }^{21}$ Thus, institutions with policies supporting flexibility and work-life integration may have an edge in recruitment and retention.

The benefits of improving policies for part-time faculty were heralded in a recent report in Academic Medicine on behalf of the Alliance for Academic Internal Medicine. ${ }^{22}$ The consensus statement argues that part-time faculty report higher job satisfaction, less burnout, and more work control than full-time physicians. Thus, increasing the number of part-time faculty among the ranks could enrich a department by enhancing faculty morale and productivity. ${ }^{23}$ In addition, part-time faculty provide cost-effective, high-quality patient care, research, and education. The task force recommended steps for institutions to adopt in recruiting and using parttime faculty. Along with creating part-time positions, lengthening promotion and tenure clocks, and respecting work-life integration, they recommended considering parttime faculty for leadership positions, grant applications, awards, and researching "best practices" for integrating parttime faculty into a department. ${ }^{22}$

These are not new ideas in the corporate world, and it was not surprising to find that they are underused in the higher education institutions in our study. Many companies are meeting demands for flexibility and targeting the recruitment and retention of women, while reporting high levels of productivity, employee satisfaction, and a healthy bottom line. A compendium of interesting programs can be found among the annual award winners of Catalyst, a nonprofit organization focused on women in the workplace (www.catalyst.org). Deloitte LLP, for example, has been recognized for its programs designed to support women employee retention and career development. They use creative approaches, such as their Mass Career Customization program, in which twice yearly all employees review how they want to work in four categories: workload, career pace, location, and schedule (including travel and telecommuting). Depending on circumstances, employees can choose to scale up or down on any or all areas. Such efforts have greatly increased the number of women in leadership positions at Deloitte LLP and reduced their attrition gap between men and women. ${ }^{24,25}$

Academic medical centers and institutions of higher education are far less nimble than corporations and tend to be slower in policy innovations, but the talent war is no less competitive. Factors contributing to the lack of progress in adopting flexible policies at academic health centers could stem from leadership challenges, new faculty concerns, and a clash of cultures between the medical school and other schools in institutions. Department chairs face real financial pressures that may orient them to focus more on short-term productivity rather than long-term faculty development, satisfaction, and success. Additionally, new faculty recruits are likely just out of medical or graduate school, relatively naive to issues surrounding progressive work-life policies, untrained in negotiating skills, and more focused on securing a position than challenging the system. Additionally, faculty in academic health centers may be caught between the policies of the parent university system, the partner hospital(s), and the faculty practice plan(s).

This complexity is often unique to faculty in the health professions and can create a culture divide with other schools in the same institution, yet faculty policy changes, such as those described in this article, are frequently made at the institutional level, beyond the scope of the medical school. Institutional strategies to implement policy change must involve a transparent process to identify problematic policies, research available or comparative options, include faculty opinion, and ensure fair procedure. Programs, such as the ACE/Alfred P. Sloan Foundation, that fund initiatives to support faculty career flexibility will be critical to bringing increasingly innovative practices into academe. When the majority of recruited faculty require flexibility, pressure to improve and compete for talent will grow. More creative solutions may come to light, such as flexible standards for leaves of absences ("on and off ramps"), ancillary support services that help faculty integrate personal and professional roles, and increased public-private partnerships for such needs as child and elder care.

In addition to adding to an institution's competitiveness, progressive work-life policies can be thought of as an investment, not a cost, with potentially significant returns in recruitment, retention, advancement, and faculty satisfaction. With the overarching goal of faculty satisfaction, examining qualitatively which policies are most important to which groups of faculty at what time in their career would provide useful feedback. Where a cost-benefit analysis of these policies may seem useful in understanding how best to use limited resources, university governing bodies must be convinced that investing upfront in flexible work-life policies has the potential to harvest more substantial long-term benefits. Knowing which policies, for example, are most strongly associated with women faculty recruitment and retention could save funds in the long term by decreasing attrition and increasing promotion and advancement. Because such issues as advancement in rank are longitudinal questions, given the time until tenure and promotion, schools with innovative policies will need to be studied over time, and institutional leaders will need to maintain a long-range view of these complex issues.

\section{Limitations}

There are several limitations that warrant discussion. First, although we assessed university policies available at Big Ten institutions, many academic medicine faculty have dual appointments with clinical practice plans, and these work-life policies were not assessed. These policies have a great impact on the experience of academic physicians; however, many practice plans do not make such policies publicly available and are more difficult to access. Thus, it is difficult to know 
how practice plan benefits may supplement or detract from the university policies. Second, this study is cross-sectional and does not represent change in policies over time. Third, the presence of a policy does not always translate into the use of a policy, as faculty may experience subtle pressure or negative feedback in taking medical leaves or extending probationary periods. Further comparison studies to examine policy use and departmental or institutional climate surrounding such policy pressures or biases would be useful.

Fourth, given this study's sample, our findings are not necessarily generalizable. However, because our results were similar to (and even less variable than) those of Bristol et al., ${ }^{17}$ these data together likely represent what many institutions have implemented in terms of work-life policies. Fifth, we were unable to validate our online assessments of the policies of two institutions. Among those that did validate the results, however, the data remained unchanged. In general, these data are retrievable online although not always readily accessible. Additionally, many Big Ten institutions, including University of Wisconsin, University of Michigan (both in 2001), University of Illinois (2005), Michigan State University, and Ohio State University (2008), have received funding to advance women in engineering and science through the National Science Foundation (NSF) ADVANCE grant mechanisms. University of Wisconsin also previously received recognition for a particular program from the Sloan Foundation. These funding mechanisms may have created an impetus to increase flexibility at those institutions, but it is not clear to what extent these policies applied to faculty in the academic medical center, and it may also be too soon to fully realize the impact of such policies. In fact, we do not yet fully know how these policies relate to important measures of faculty recruitment, retention, promotion, and satisfaction. Further research is needed to assess whether these policies are, in fact, correlated with these outcomes.

\section{Conclusions}

In order to raise awareness, all institutions should take the challenge of examining and scoring their own work-life policies and compare them to other institutions. A healthy competition and knowledge of problematic issues will help to promote more progressive policies among less progressive schools and ultimately help to promote a more productive workplace, conducive to employing individuals needing varying amounts of flexibility to excel at their work. The single greatest resource of any academic institution is the faculty. Recruitment, retention, and advancement of the most talented faculty are core issues for all of academe. Keeping pace with the needs and desires of faculty members in today's competitive environment is a critical institutional leadership issue. Policies supporting work-life integration are not solely issues for women but for anyone needing flexibility who does not fit the mold of the faculty member who can devote countless hours to his or her career. The institutions with the most flexible policies may be those most likely to win the talent war.

\section{Acknowledgments}

We recognize the Women's Advisory Council, with the support of the Dean's Office for Faculty Affairs and Profes- sional Development, at Indiana University School of Medicine for their input and encouragement regarding this study. We appreciate Marsha Quarles' administrative support. We also thank all participating medical schools for helping to validate these data and contributing to this research.

This work was previously presented as a Poster presentation at the AAMC Annual Meeting, Washington, DC, November 2010: Flexibility in Work-Life Policies for "Big Ten" University Medical School Faculty, by J.L. Welch, S.E. Wiehe, V. Palmer-Smith, and M.E. Dankoski.

\section{Disclosure Statement}

The authors have no conflicts of interest to report.

\section{References}

1. Association of American Medical Colleges. Women in U.S. Academic Medicine: Statistics and benchmarking report 2008-2009, 2009.

2. Valian V. Why so slow: The advancement of women. Cambridge, MA: MIT Press, 1999.

3. Wenneras C, Wold A. Nepotism and sexism in peer-review. Science 1997;387:341-343.

4. Trix F, Psenka C. Exploring the color of glass: Letters of recommendation for female and male medical faculty Discourse Society. 2003;14:191-220.

5. Ash AS, Carr PL, Goldstein R, Friedman RH. Compensation and advancement of women in academic medicine: Is there equity? Ann Intern Med 2004;141:205-212.

6. Bickel J, Wara D, Atkinson BF, et al. Increasing women's leadership in academic medicine: Report of the AAMC Project Implementation Committee. Acad Med 2002 2002;77: 1043-1061.

7. Jagsi R, Guaneial E, Worobey CC, et al. The "gender gap" in authorship of academic medical literature - A 35-year perspective. N Engl J Med 2006;355:281-287.

8. Jagsi R, Motomura AR, Griffith KA, Rangarajan S, Ubel PA. Sex differences in attainment of independent funding by career development awardees. Ann Intern Med. 151:804811.

9. Shollen SL, Bland CJ, Finstad DA, Taylor AL. Organizational climate and family life: How these factors affect the status of women faculty at one medical school. Acad Med 2009;84:8794.

10. Carr PL, Ash AS, Friedman RH, et al. Relation of family responsibilities and gender to productivity and career satisfaction of medical faculty. Ann Intern Med 1998;129:532538.

11. Mason MA, Goulden M. Do babies matter (Part II)? Closing the baby gap. Academe 2004;90:10-15.

12. National Academy of Sciences. Beyond bias and barriers: Fulfilling the potential of women in academic science and engineering. Washington, DC: National Academies Press, 2006.

13. Bickel J, Brown AJ. Generation X: Implications for faculty recruitment and development in academic health centers. Acad Med 2005;80:205-210.

14. McCracken D. Winning the talent war for women. Harvard Business Rev 2000;78:159-167.

15. American Council on Education. An agenda for excellence: Creating flexibility in tenure track faculty careers, 2005.

16. Lester J, Sallee M, eds. Establishing the family-friendly campus: Models for effective practice. Sterling, VA: Stylus Publishing, 2009. 
17. Bristol MN, Abbuhl S, Cappola AR, Sonnad SS. Work-life policies for faculty at the top ten medical schools. J Womens Health 2008;17:1311-1320.

18. Big Ten Conference. Wikipedia, the free encyclopedia. Available at en.wikipedia.org/wiki/Big_Ten Accessed August 9, 2010.

19. The College Sustainability Report Card. 2010. Available at www.greenreportcard.org/report-card-2010 Accessed January 6, 2010.

20. Lancaster L, Stillman D. When generations collide. New York: HarperCollins, 2002.

21. Bickel J, Brown AJ. Generation X: Implications for faculty recruitment and development in academic health centers. Acad Med 2005;80:205-210.

22. Linzer M, Warde C, Alexander R, et al. Part-time careers in academic internal medicine: A report from the Association of Specialty Professors Part-Time Careers Task Force on behalf of the Alliance for Academic Internal Medicine. Acad Med 2009;84:1395-1400.
23. Mechaber H, Levine R, Manwell L, et al. Part-time physicians...prevalent, connected, and satisfied. J Gen Intern Med 2008;23:300-303.

24. Benko C, Weisberg A. Mass career customization: Aligning the workplace with today's nontraditional workforce. Boston: Harvard Business School Press, 2007.

25. Adams S. Making a female-friendly workplace. Forbes Magazine, April 16, 2010.

Address correspondence to: Julie L. Welch, M.D.

Indiana University School of Medicine Department of Emergency Medicine

Methodist Hospital Emergency Medicine and Trauma Center

1701 N. Senate Boulevard, AG 001 Indianapolis, IN 46202

E-mail: jlwelch@iupui.edu 